\title{
Testing the Supplementary Cementitious Material Based on GGBFS and Zeolite for Prediction of the Activity Index ${ }^{+}$
}

\author{
Marek Kovac *, Alena Sicakova and Matej Spak \\ Faculty of Civil Engineering, Technical University of Košice, 04000 Košice, Slovakia; \\ alena.sicakova@tuke.sk (A.S.); matej.spak@tuke.sk (M.S.) \\ * Correspondence: marek.kovac@tuke.sk; Tel.: +421-55-602-4114 \\ + Presented at Environment, Green Technology and Engineering International Conference (EGTEIC 2018), \\ Caceres, Spain, 18-20 June 2018.
}

Published: 19 October 2018

\begin{abstract}
The article deals with cement supplementary materials based on ground granulated blast furnace slag and zeolite. Purpose of the experiment was to observe dependences (if they exist) between selected parameters (modulus of basicity, modulus of hydraulicity and initial setting time) and activity indexes, for easier and quicker way to determine or predict the activity index. Testing showed that moderate dependences between those parameters and activity indexes were observed. Results showed that prediction of activity indexes based on chemical composition is feasible.
\end{abstract}

Keywords: mineral additives; activity index prediction; zeolite

\section{Introduction}

Natural zeolite is used in many fields of industry. It has optimal chemical and mineralogical composition to be used as SCM. It usually contains more than $70 \%$ of $\mathrm{SiO}_{2}$ and also high amount of $\mathrm{Al}_{2} \mathrm{O}_{3}$. The pozzolanic reaction in pastes containing zeolite of clinoptilolite type considerably decreases the calcium hydroxide content [1]. Concrete modified by natural zeolite has several interesting properties comparing to Portland cement based concrete-the bleeding and segregation in the fresh state is reduced, as well as the viscosity is increased [2]. Use of natural zeolite also increases the water demand of concrete, thus higher amounts of high range water reducer are needed to maintain the uniform flow [3,4]. Zeolite with higher specific surface areas has the highest rate of pozzolanic reactivity. Superplasticizer demand and workability retention and admixture demand pose a severe limitation on the application of zeolite [5]. Therefore, the zeolite can be a useful material only in applications where workability is of no significant importance. The mechanical properties of concretes are influenced by the amount of zeolite. In regard to pozzolanic nature of zeolite, initial strength is usually lower in comparison with Portland cement only concrete. Addition of natural zeolite delay the strength development during the first 7 days, after which concretes having $10 \%$ natural zeolite provided almost similar compressive strength to that of reference concretes[1].

More conventional addition for concrete is ground granulated blast furnace slag (GGBFS). Blast furnace slag is a byproduct acquired in the production of iron in the blast furnace and is involving essentially of silicates and alumino-silicates of calcium and of other bases [6]. This SCM is widely used for concrete production for several decades because of its contributions to concrete properties. GGBFS has a positive influence on the workability of fresh concrete. The test results of research by Erdogan et al. [7] revealed that GGBFS-based concretes demonstrate enhanced workability compared to the concrete without GGBFS. When concreting massive structures, GGBFS is used to control the heat of reaction. Also, the use of GGBFS influences the strength characteristics of concrete which has 
a profound bearing on the performance of concrete in pre-stressing work along with reinforced concrete. Also it is necessary for concrete elements being exposed to aggressive environments. Compressive strength of GGBFS-based concrete has been found to be lower than the compressive strength of plain concrete at all ages and for all percentage of cement replacements (20, 40 and $60 \%$ ) [8].

\section{Experiment}

The article focuses on the pozzolanic activity as a key parameter of supplementary cementitious materials $(\mathrm{SCM})$ which influences final properties of cement composites. Pozzolanic activity is a parameter which is controlled prior to certification of cementitious product (concrete additive) and it is controlled during manufacturing process as well. It is expressed based on compressive strength of mortar samples prepared with the cement only and the samples prepared using defined portion of additive being tested, after 7 and 28 days of hardening. So the process of finding the parameter is relatively time-consuming. Thus, the main goal of experiment was examining the possibility of prediction the pozzolanic activity by simpler way, on the basis of chemical composition of SCM (expressed by modulus of basicity and by modulus of hydraulicity), or on the basis of setting time.

\subsection{Materials}

The main subject of presented experiment is the investigation of ZEOSLAG product as supplementary cementitious material, which is a combination of ground granulated blast furnace slag (GGBFS) and zeolite. Cement and Zeolite were used as reference materials.

Following materials were used in the experiment:

- Cement CEM I 42.5 N in accordance with EN 197-1.

- $\quad$ Silica sand of 0/2 fraction (standardized gradation) in accordance with EN 196-1.

- Zeoslag: 6 different samples (A-F), having the GGBFS/Z ratio 90/10, were taken into the experiment. They differ in production and milling process. This has an impact on the chemical composition, as it is given in Table 1.

- Zeolite: natural zeolite, chemical composition is given in Table 1.

Table 1. Chemical composition of materials.

\begin{tabular}{cccccc}
\hline Material & $\mathbf{M g O}[\%]$ & $\mathrm{Al}_{2} \mathrm{O}_{3}[\%]$ & $\mathrm{SiO}_{2}[\%]$ & $\mathrm{CaO}[\%]$ & $\mathrm{Fe}_{2} \mathrm{O}_{3}[\%]$ \\
\hline CEM I 42.5 N & 9.0 & 3.0 & 20.3 & 64.1 & 3.0 \\
Zeoslag A & 9.0 & 7.1 & 47.3 & 32.3 & 0.4 \\
Zeoslag B & 9.7 & 7.5 & 48.2 & 31.3 & 0.4 \\
Zeoslag C & 6.1 & 4.9 & 29.1 & 15.9 & 0.2 \\
Zeoslag D & 4.0 & 2.9 & 16.7 & 7.1 & 0.1 \\
Zeoslag E & 8.4 & 7.4 & 48.5 & 31.4 & 0.4 \\
Zeoslag F & 7.4 & 6.8 & 43.4 & 23.1 & 0.4 \\
Zeolite & 1.2 & 11.6 & 78.8 & 3.5 & 1.7 \\
\hline
\end{tabular}

\subsection{Methods}

Following methods of testing were used:

- Chemical composition was determined using XRF analysis. The main oxides $\left(\mathrm{MgO}, \mathrm{Al}_{2} \mathrm{O}_{3}, \mathrm{SiO}_{2}\right.$, $\mathrm{CaO}$ and $\mathrm{Fe}_{2} \mathrm{O}_{3}$ ) are given in Table 1 . and they were used for calculation of modulus,

- determining the amount of water for standard consistency of binder paste (STN EN 196-3: Methods of testing cement. Part 3: Determination of setting times and soundness),

- initial setting time IST (STN EN 196-3: Methods of testing cement. Part 3: Determination of setting times and soundness),

- compressive strength ( $f_{c}$ ) 2, 7 and 28 days of setting and hardening (STN EN 196-1: Methods of testing cement. Part 1: Determination of strength), 
- $\quad$ activity index (AI) after 2, 7 and 28 days of setting and hardening (STN EN 15167-1 Ground granulated blast furnace slag for use in concrete, mortar and grout. Part 1: Definitions, specifications and conformity criteria).

As given above, samples of mixtures for testing the strength characteristics and calculating the activity index were prepared according to standard for testing the GGBFS. The binder here consists of $50 \%$ of additive to be tested and 50\% of cement. Whole mixture is as follows: $225 \mathrm{~g}$ of cement, 225 $\mathrm{g}$ of additive, $225 \mathrm{~g}$ of water and $1350 \mathrm{~g}+/-5 \mathrm{~g}$ of normalized sand. Next, the activity index is calculated as a ratio of compressive strength of this mixture and compressive strength of sample consisting of $100 \%$ of cement.

Following criteria for the activity index are given in the standard: it should be higher than $45 \%$ after 7 days and higher than $70 \%$ after 28 days of setting and hardening. Modulus of basicity $(\mathrm{Mb}=$ $\left.\mathrm{CaO}+\mathrm{MgO} / \mathrm{SiO}_{2}+\mathrm{Al}_{2} \mathrm{O}_{3}\right)$ and modulus of hydraulicity $\left(\mathrm{Mh}=\mathrm{CaO} / \mathrm{SiO}_{2}+\mathrm{Al}_{2} \mathrm{O}_{3}+\mathrm{Fe}_{2} \mathrm{O}_{3}\right)$ were calculated and then, for the prediction of $\mathrm{AI}_{2}, \mathrm{AI}_{7}$ and $\mathrm{AI}_{28}$ activity indexes, the dependences between them and indicators given above were found.

\section{Results and Discussion}

\section{Dependences for Prediction of Activity Indexes}

Figures 1 and 2 show dependence between modulus of basicity (and modulus of hydraulicity respectively) and activity indexes in 2, 7, and 28 days of all kinds of Zeoslags. They show that moderate strength correlation exists between modulus of basicity/hydraulicity and activity index $\mathrm{AI}_{28}$. Activity indexes $\mathrm{AI}_{7}$ and $\mathrm{AI}_{2}$ showed tight dependence on both of modulus.

Figure 3 shows dependence between initial setting time and activity index IA 28 of all kinds of Zeoslags. Moderate strength correlation exists between initial setting time and activity index $\mathrm{AI}_{28}$.

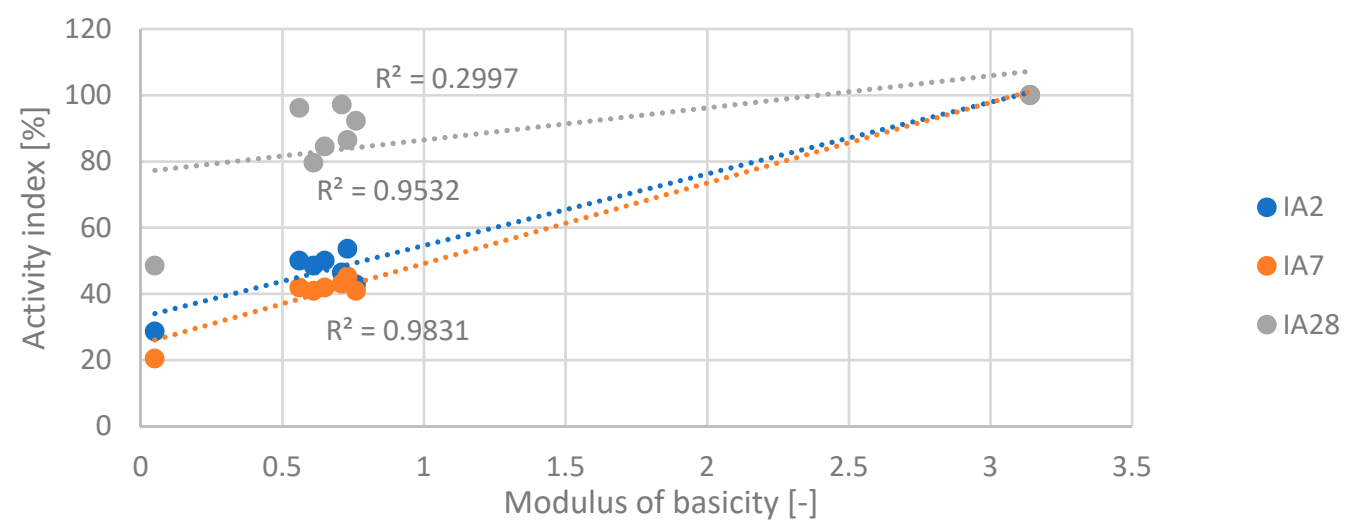

Figure 1. Dependence between modulus of basicity and activity indexes calculated in 2, 7, and 28 days.

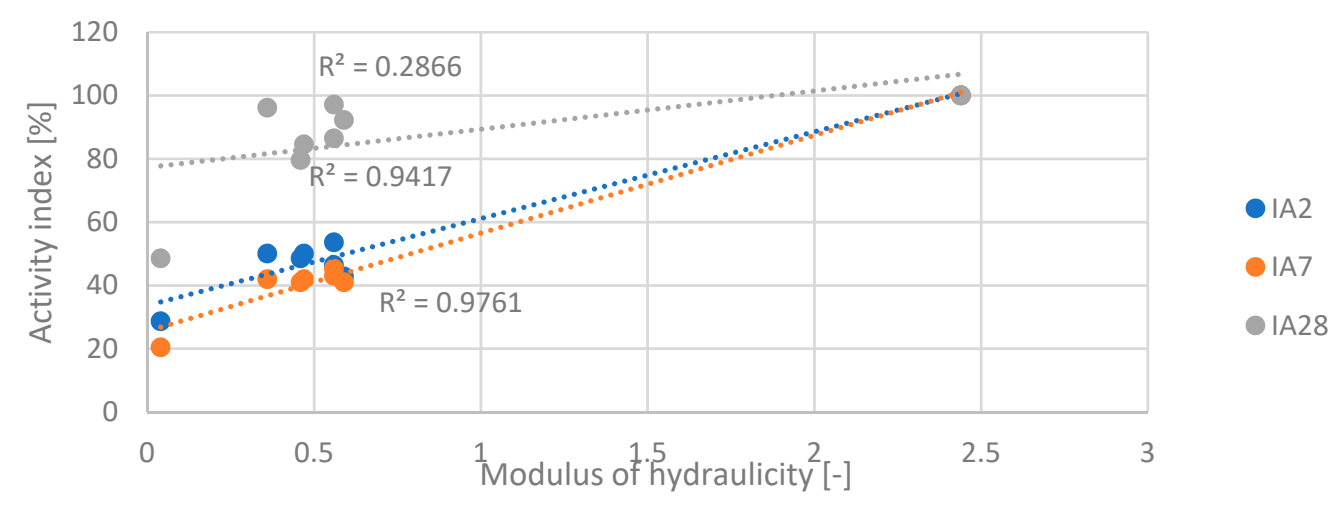

Figure 2. Dependence between modulus of hydraulicity and activity indexes calculated in 2,7 , and 28 days. 


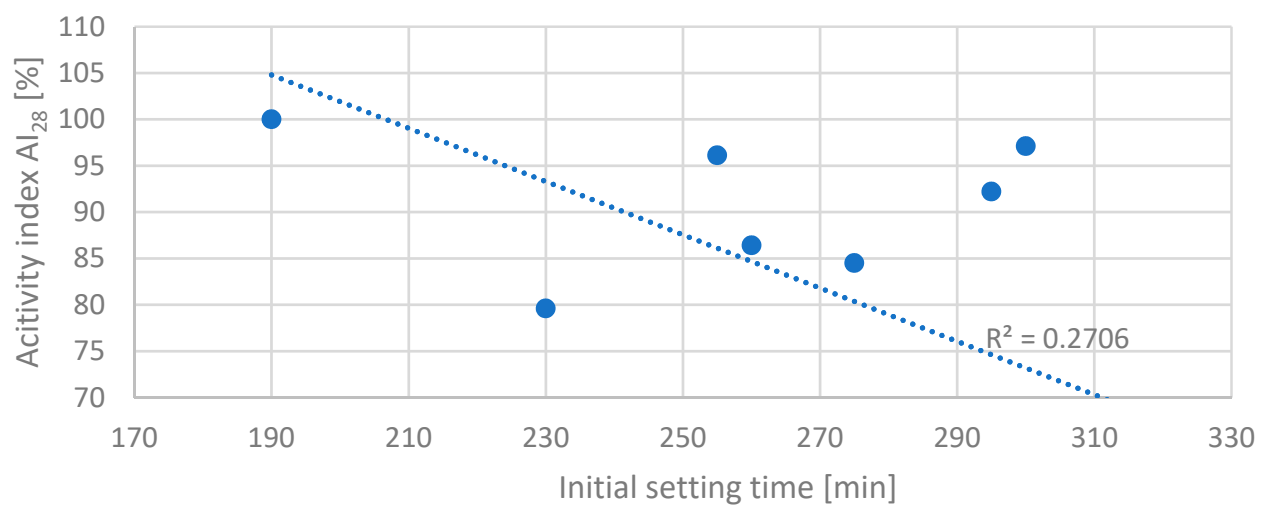

Figure 3. Dependence between initial setting time and activity index calculated in 28 days.

\section{Conclusions}

Based on results of the experiment the following conclusions can be made:

- the moderate dependence between modulus of basicity and indexes of activities was found, so the prediction of activity index $\mathrm{AI}_{28}$ based on modulus of basicity is possible but questionable,

- the moderate dependence between modulus of hydraulicity and indexes of activities was found too, so the prediction of activity index $\mathrm{AI}_{28}$ based on modulus of hydraulicity is also possible,

- the moderate strength dependence between initial setting time and indexes of activities was found, the prediction of the activity index $\mathrm{AI}_{28}$ based on initial setting time could be determined however more testing should be performed I order to confirm or determine stronger dependence. This also applies to activity index prediction based on modulus of basicity and modulus of hydraulicity.

Acknowledgments: This work was supported by the Grant No. 1/0524/18 of the Slovak Grant Agency for Science.

\section{References}

1. Markiv, T.; Sobol, K.; Franus, M.; Franus, W. Mechanical and durability properties of concretes incorporating natural zeolite. Arch. Civ. Mech. Eng. 2016, 16, 554-562.

2. Feng, N.Q.; Li, G.Z.; Zang, X.W. High-strength and flowing concrete with a zeolitic mineral admixture. Cem. Concr. Aggreg. 1990, 12, 61-69.

3. Ramezanianpour, A.A.; Mousavi, R.; Kalhori, M.; Sobhani, J.; Najimi, M. Micro and macro level properties of natural zeolite contained concretes. Constr. Build. Mater. 2015, 101, 347-358.

4. Quanlin, N.; Naiqian, F. Effect of modified zeolite on the expansion of alkaline silica reaction. Cem. Concr. Res. 2005, 35, 1784-1788.

5. Ghafari, E.; Feys, D.; Khayat, K. Feasibility of using natural SCMs in concrete for infrastructure applications. Constr. Build. Mater. 2016, 127, 724-732.

6. Özbay, E.; Erdemir, M.; Durmuş, H.İ. Utilization and efficiency of ground granulated blast furnace slag on concrete properties-A review. Constr. Build. Mater. 2016, 105, 423-434.

7. Johari, M.M.; Brooks, J.J.; Kabir, S.; Rivard, P. Influence of supplementary cementitious materials on engineering properties of high strength concrete. Constr. Build. Mater. 2011, 25, 2639-2648.

8. Shariq, M.; Prasad, J.; Masood, A. Effect of GGBFS on time dependent compressive strength of concrete. Constr. Build. Mater. 2010, 24, 1469-1478.

(C) 2018 by the authors. Licensee MDPI, Basel, Switzerland. This article is an open access article distributed under the terms and conditions of the Creative Commons Attribution (CC BY) license (http://creativecommons.org/licenses/by/4.0/). 